\title{
Cardiac release of chemoattractants after ischaemia induced by coronary balloon angioplasty
}

Franz-Josef Neumann, Gert Richardt, Maria Schneider, Ilka Ott, Heide-Marlen Haupt, Harald Tillmanns, Albert Schömig, Bernhard Rauch

\begin{abstract}
Objective-To investigate the release of chemoattractants after myocardial ischaemia during balloon angioplasty.

Design-Sampling of femoral arterial and coronary sinus blood before and immediately after the first balloon inflation during angioplasty. In a study group of 16 patients the balloon was kept expanded for two minutes, whereas in a control group of eight patients the first balloon inflation was brief $(<10 \mathrm{~s})$.
\end{abstract}

Main outcome measures-Chemotaxis of neutrophils from healthy donors towards patient plasma (Boyden chamber), superoxide anion production by normal neutrophils after incubation with patient plasma (cytochrome $C$ reduction). Results-In the study group, coronary sinus plasma after balloon deflation was more chemoattractive to normal neutrophils (median relative increase $24 \%$ (quartiles: $4 \%, 45 \%$ ), $p=0.008$ ) and induced a higher superoxide anion production in normal neutrophils (44\% $(10 \%, 97 \%), p=0.013)$ than arterial plasma. Concomitantly, the degree of activation of patient neutrophils was increased in coronary sinus blood compared with arterial blood, as shown by an increased proportion of neutrophils reducing nitroblue tetrazolium $(21 \%(9 \%, 38 \%), p=$ $0 \cdot 006$ ) and a decreased neutrophil filterability $(-16 \%(-3 \%,-40 \%), p=0.003)$ in coronary sinus blood. In the study group before balloon inflation and in the control group before and after balloon inflation differences between arterial and coronary sinus blood were not significant. Signs of ischaemia (lactate release, ST segment changes) were only detected in the study group.

Conclusion-After transient myocardial ischaemia during balloon angioplasty there is a local release of chemoattractants, associated with neutrophil activation.

(Br Heart f 1993;70:27-34)

Recent experiments suggest that interactions between leucocytes, platelets, and endothelial cells may cause microvascular injury in myocardial ischaemia. ${ }^{1-4}$ These cell to cell interactions involve an ongoing release of chemoattractants and cytokines ${ }^{5-7}$ and a pro- gressive cell activation with discharge of various toxic compounds predominately derived from leucocytes. ${ }^{1}$ Consistent with these concepts, changes in neutrophil function suggestive of cell activation have been found in peripheral and coronary sinus blood of patients with symptomatic coronary artery disease. ${ }^{89}$ The changes even occur in stable angina, ${ }^{89}$ when myocardial ischaemia is transient and brief. During percutaneous transluminal coronary angioplasty (PTCA), repetitive short periods of myocardial ischaemia were associated with local neutrophil activation, as indicated by increased neutrophil elastase concentrations in coronary sinus blood. ${ }^{10}$ Moreover, in peripheral arterial occlusive disease with intermittent claudication short periods of ischaemia cause local alterations of neutrophil function. ${ }^{11}$

In coronary artery disease it is not known whether the changes in neutrophil function in stable angina or those found after PTCA are due to myocardial ischaemia itself or to processes occurring at the atherosclerotic plaque..$^{8-1012}$ The purpose of our study was to find whether transient coronary occlusion during PTCA induces a release of chemoattractants with neutrophil activation that can be related to the ischaemia.

\section{Patients and methods}

PATIENTS

The study group comprised 24 patients (18 men, six women, median age 56 (quartiles: $48,64)$ ) with single vessel disease undergoing elective PTCA of a left anterior descending coronary artery (LAD) stenosis proximal to the first septal perforator. The stenoses had to show an area reduction of $70 \%$ or more on interactive computerised analysis (CRP $\mathrm{GmbH}$, Konstanz, Germany) and had to be classified as type A. ${ }^{13}$ All patients had chronic stable angina of Canadian Cardiovascular Society functional class III. ${ }^{14}$ The indication for PTCA was based on a low threshold (work load $\leqslant 100 \mathrm{~W}$ ) for exercise induced myocardial ischaemia on bicycle ergometry. Patients with detectable collateral blood supply to the distal $\mathrm{LAD}$, previous $\mathrm{Q}$ wave infarction, or a history of non $Q$ wave infarction as well as those with interfering non-cardiac diseases, such as inflammatory disorders, malignancy, or diabetes mellitus, were not eligible for the study.

The study was approved by the institutional ethics committee for human subjects. All patients gave written informed consent. 
STUDY PROTOCOL

During the study, patients were kept on aspirin $(100 \mathrm{mg} /$ day) and short acting oral nitrates, but the rest of their medication had been discontinued for at least five half lives. After premedication by $10 \mathrm{mg}$ diazepam given orally and local anaesthesia, the coronary sinus was cannulated through the right internal jugular vein with a $7 \mathrm{~F}$ multipurpose catheter. A 9F femoral artery sheath was inserted percutaneously under local anaesthesia and 10000 IU of heparin were given intra-arterially. Balloon diameters when inflated ranged from $2.5 \mathrm{~mm}$ to $3.5 \mathrm{~mm}$, depending on the size of the normal vessel segment adjacent to the stenosis. The guide wire of the balloon catheter was placed in the stenosis with the aid of fluoroscopy. Up to this point $25 \mathrm{ml}$ to $65 \mathrm{ml}$ of contrast medium (Solutrast, Byk-Gulden, Konstanz, Germany) had been used to manipulate the coronary sinus catheter and the balloon catheter.

Immediately after positioning the guide wire for the balloon catheter, blood samples were drawn simultaneously from the coronary sinus and from the femoral artery for one minute. Without any further application of contrast medium, the balloon was placed in the stenosis and inflated. In the study group of 16 patients the balloon was kept fully expanded for two minutes. In the control group of eight patients, however, the balloon was only briefly inflated until full expansion was achieved (<10 s). Immediately after deflation of the balloon, a second set of blood samples was drawn simultaneously from the coronary sinus and from the femoral artery for one minute. The blood samples were put on ice and processed immediately.

\section{EFFECT OF PATIENT PLASMA ON NORMAI} NEUTROPHILS

Normal neutrophils were taken from healthy donors. Preparation of neutrophils by density gradient separation was performed at $4^{\circ} \mathrm{C} . .^{15} 16$ Blood samples $(50 \mathrm{ml})$ were anticoagulated with CPDA (Na-citrate, phosphate buffer, dextrose, adenine; Fa Greiner, Nürtingen, Germany) and were mixed with $15 \mathrm{ml}$ of $3 \%$ dextran in normal saline (w/v, MW 266000 $\mathrm{g} / \mathrm{mol}$ ). After sedimentation the supernatant was collected. Residual erythrocytes were lysed in $15 \mathrm{ml}$ ice cold distilled water, and after 25 seconds, isotonicity was reconstituted by addition of $5 \mathrm{ml} 3 \cdot 6 \% \mathrm{NaCl}$. Leucocytes were resuspended in phosphate buffered saline (PBS) and were layered on a two step density gradient made up of Histopaque 1077 on top of Histopaque 1119 (Sigma, Deisenhofen, Germany). After centrifugation at $800 \mathrm{~g}$ for 20 minutes the lower white cell band was harvested, washed twice, and resuspended in PBS. The yield ranged between $40 \%$ and $60 \%$ of the neutrophils in whole blood. Ninety seven per cent of the cells collected were neutrophils with more than $95 \%$ viable cells (trypan blue exclusion).

Chemoattractiveness of patient plasma was assessed by the method of Boyden. ${ }^{17} 18$ In essence, neutrophils from one single sample of a normal donor were exposed to various plasma samples of a single patient. Each experiment was performed in duplicate. A 48 well microchemotaxis chamber ${ }^{18}$ (NeuroProbe, distributed by Nuclepore, Tübingen, Germany) was used with polycarbonate filters (3.0 $\mu \mathrm{m}$ pores, Nuclepore $\mathrm{GmbH}$ ) to separate the upper and lower compartments. With the lower compartments containing plasma samples diluted by an equal volume of PBS, the mounted microchemotaxis chambers were preincubated at $37^{\circ} \mathrm{C}$ in humidified air with $5 \% \mathrm{CO}_{2}$ for 30 minutes. After filling the upper compartments with control neutrophils in PBS ( $5 \times 10^{5}$ cells $\left./ \mathrm{ml}\right)$, the microchambers were kept under the same conditions for another 80 minutes. Thereafter, the filters were removed and the neutrophils at the side of the filter facing the upper compartment were wiped off. After air drying and staining with Wright's stain (Sigma, Deisenhofen, Germany) the number of cells migrated was counted in five high power fields (magnification $\times 400$ ). The effect of patient plasma on chemokinesis of control neutrophils was assessed in additional experiments. In these experiments the neutrophils contained in the upper compartments were suspended in the same diluted plasma samples as were put into the lower compartments.

To assess the stimulation by patient plasma of superoxide anion production in control neutrophils, the cells were incubated with patient plasma at $37^{\circ} \mathrm{C}$ for 15 minutes. Then control neutrophils were resuspended in PBS and washed twice. Superoxide anion production was measured by the superoxide dismutase (SOD) inhibited reduction of cytochrome $\mathrm{C}$ as described by Babior et al ${ }^{19}$ The standard reaction mixture contained $2.5 \times 10^{5}$ neutrophils, $45 \mu \mathrm{mol} / 1$ cytochrome $\mathrm{C}$ (from horse, Sigma) with or without 1000 $\mathrm{U} / 1$ SOD (specific activity $30000 \mathrm{U} / \mathrm{mg}$, Sigma), and enough Hank's balanced salt solution to make a final volume of $0.5 \mathrm{ml}$. The mixtures were incubated at $37^{\circ} \mathrm{C}$ for 15 minutes before the reaction was stopped by putting the vials on ice. After centrifugation at $4^{\circ} \mathrm{C}$, the SOD inhibited reduction of cytochrome $\mathrm{C}$ was found in the supernatant by measuring absorbance at $550 \mathrm{~nm}\left(\mathrm{E}_{550 \mathrm{~nm}}\right.$ $=2.11 \times 10^{4} \mathrm{M}^{-1} \mathrm{~cm}^{-1}$, Twinreader, Flow Laboratories, Meckenheim, Germany). Results are expressed as nmol superoxide anions / $5 \times 10^{5}$ neutrophils $/ 15 \mathrm{~min}$. All experiments were performed in triplicate.

FUNCTION TESTS IN PATIENT NEUTROPHILS

The proportion of activated neutrophils was assessed by the nitro blue tetrazolium test. This was performed on freshly drawn heparinised blood samples $(20 \mathrm{U} / \mathrm{ml})$ by a modification of the method of Park et al ${ }^{20}$ as described earlier. ${ }^{11}$ Briefly, the blood specimens were incubated at $37^{\circ} \mathrm{C}$ for 15 minutes with an equal volume of an $0.1 \%$ solution of nitro blue tetrazolium (Sigma, Deisenhofen, Germany) in PBS ( $\mathrm{pH} \mathrm{7.2)}$ and then kept at room temperature for another 15 minutes. Smears were prepared and stained by 
Table 1 Baseline characteristics of the study population

\begin{tabular}{llll}
\hline & $\begin{array}{l}\text { Study group } \\
(n=16)\end{array}$ & $\begin{array}{l}\text { Control group } \\
(n=8)\end{array}$ & $p$ Value \\
\hline Age & $54(48,64)$ & $56(51,64)$ & 0.67 \\
M/F & $13 / 3$ & $5 / 3$ & 0.62 \\
Degree of stenosis (\% area) & $92(85,95)$ & $90(83,94)$ & 0.58 \\
Inflation pressure (atm) & $4 \cdot 8(4,5)$ & $4 \cdot 5(4 \cdot 3,5 \cdot 3)$ & 0.98 \\
ST segment deviation (sum of $\mathrm{V}_{2} \mathrm{~V}_{4} \mathrm{~V}_{6}(\mathrm{mV})$ & $0.5(0 \cdot 38,0 \cdot 68)$ & $0(0,0)$ & 0.001 \\
\hline
\end{tabular}

Values are median (quartiles).

Wright's stain (Sigma). The percentage of neutrophils containing formazan deposits of at least the size of a lobe of the nucleus was designated as a positive nitro blue tetrazolium score.

Passive neutrophil deformability was analysed by the method of Nash et al. ${ }^{21}$ In essence, after discarding platelet rich plasma, neutrophils were separated from ethylene diamine tetraacetate (EDTA) anticoagulated blood by means of a two step density gradient made up of Histopaque 1077 on top of Histopaque 1119. Purified neutrophils were resuspended in PBS containing $1 \mathrm{~g} / 1$ EDTA and $5 \%$ autologous plasma, and the cell concentration was adjusted to $5 \times 10^{5}$ neutrophils/ml. Neutrophil filtration was performed in a St George's filtrometer (Carri-Med, Dorking, England) with polycarbonate membrane filters (Nuclepore, Tübingen, Germany), nominal pore diameter $8 \mu \mathrm{m}$. Filtration was carried out under constant pressure of $294 \mathrm{~Pa}\left(=3 \mathrm{~cm} \mathrm{H}_{2} \mathrm{O}\right)$. With a microcomputer linked to the filtrometer (software by Carri-Med, Dorking, England) the relative filtration rate (with respect to buffer alone) after filtration of $1 \mathrm{ml}$ of neutrophil suspension (the so called late relative filtration rate) was determined as a measure of neutrophil filterability.

\section{OTHER METHODS}

The cells were counted with a Coulter Counter, Model ZF (Coulter Electronics, Herts, England). Blood smears were examined by an experienced technician. Total neutrophils were evaluated by multiplying the white cell count by the differential neutrophil count. Lactate concentrations were measured enzymatically with a standard kit (Boehringer Mannheim, Germany).

STATISTICAL ANALYSIS

Results are reported as median (quartiles) unless otherwise indicated. Differences between matched samples were tested by Wilcoxon's matched pairs signed ranks test, and differences between the study group and the control group by the Mann-WhitneyWilcoxon rank sum test. A p value $<0.05$ in the two tailed test was regarded as significant.

\section{Results}

BASELINE CHARACTERISTICS OF THE STUDY POPULATION

Table 1 shows the baseline characteristics of the study population. There were no significant differences between the control group and the study group in terms of age, sex, inflation pressure needed for full expansion, and severity of LAD stenosis before PTCA. In all patients PTCA was completed successfully and resulted in a median reduction in stenosis of $66 \%(54 \%, 81 \%)$.

In the study group, all patients experienced angina during PTCA that was accompanied by significant ST segment changes (table 1). Furthermore, immediately after balloon deflation lactate concentrations in coronary sinus blood were significantly higher than in arterial blood (table 2, fig 1B). Under resting conditions lactate concentrations did not differ significantly between coronary sinus blood and arterial blood (fig 1B).

In the control group, only one patient had angina during the first balloon inflation, but none of the patients showed significant ST segment changes (table 1). Also, lactate concentrations in coronary sinus blood did not significantly increase after balloon inflation (table 2, fig 1A).

EFFECT OF PLASMA ON NORMAL NEUTROPHILS In the study group, plasma from coronary sinus blood after balloon deflation was more chemoattractive than plasma from simultaneously taken arterial blood (table 2) and plasma from coronary sinus blood before balloon inflation (median difference: $5 \cdot 1(-0 \cdot 2,14 \cdot 6)$ cells vision field; $p=0.016$ ) (fig $2 \mathrm{~B}$ ). Concomitant significant changes in plasma induced chemokinesis, however, could not be found (not shown). Plasma stimulated superoxide anion production by normal neutrophils showed similar changes as plasma chemoattractiveness (fig 3B). After balloon deflation, plasma from coronary sinus blood

Table 2 Differences in arterial and coronary sinus blood immediately after balloon deflation in the study and control groups

\begin{tabular}{|c|c|c|c|c|c|}
\hline & \multicolumn{2}{|l|}{ Study group } & \multicolumn{2}{|l|}{ Control group } & \multirow[b]{2}{*}{$p$ Value } \\
\hline & $D$ & $D_{r e l}(\%)$ & $D$ & $D_{r e l}(\%)$ & \\
\hline Lactate $(\mathrm{mmol} / \mathrm{l})$ & $0.61(0.28,0.84)$ & $80(33,98)$ & $-0.11(-0.35,0.02)$ & $-10(-26,1)$ & 0.001 \\
\hline $\begin{array}{l}\text { Plasma chemoattract } \\
\text { (cells/vision field) }\end{array}$ & $8 \cdot 8(0 \cdot 1,13 \cdot 9)$ & $24(4,45)$ & $-1 \cdot 5(-6 \cdot 9,7 \cdot 3)$ & $-4(-21,16)$ & 0.030 \\
\hline $\begin{array}{l}\text { Stim SOP } \\
\left(\mathrm{nmol} / 5 \times 10^{5} \mathrm{cells} / 15 \mathrm{~min}\right)\end{array}$ & $0.98(0.32,2 \cdot 31)$ & $44(10,97)$ & $0.27(-0.43,0.71)$ & $27(-16,34)$ & $0 \cdot 030$ \\
\hline $\begin{array}{l}\text { PMN }(1 / \mathrm{nl}) \\
\text { NBT score }(\%) \\
\text { LFR }\end{array}$ & $\begin{aligned} & 0 \cdot 13(-0.06,0 \cdot 19) \\
& 2 \cdot 1(-0.1,3 \cdot 1) \\
- & 0.05(-0.01,-0 \cdot 18)\end{aligned}$ & $\begin{array}{c}3(-1,5) \\
21(1,38) \\
-16(-3,-40)\end{array}$ & $\begin{array}{l}0.04(-0.06,0.17) \\
-0.4(-1.9,0.6) \\
0.02(-0.02,0.07)\end{array}$ & $\begin{array}{r}1(-1,4) \\
-3(-17,6) \\
6(-4,17)\end{array}$ & $\begin{array}{l}0.65 \\
0 \cdot 013 \\
0.012\end{array}$ \\
\hline
\end{tabular}

$\mathrm{D}$, median absolute arterial and coronary sinus blood difference (quartiles); $\mathrm{D}_{\text {rell }}$ median relative arterial and coronary sinus blood difference (quartiles); $p$ values for the differences between the study group and the control group by two tailed test; lactate, serum lactate concentration; plasma chemoattract, chemoattractiveness of patient plasma to control neutrophils; stim SOP, superoxide anion production in control neutrophils stimulated by patient plasma; PMN, patient neutrop

nitro blue tetrazolium score of patient neutrophils; LFR, late relative filtration rate of patient neutrophils. 
Figure 1 Plot of femoral arterial $(F A)$ and

coronary sinus (CS) blood differences in lactate concentration before and immediately after the first balloon inflation $(A)$ in the control group (brief balloon inflation) and (B) in the study group (balloon inflation for two minutes). p Values by two tailed test.

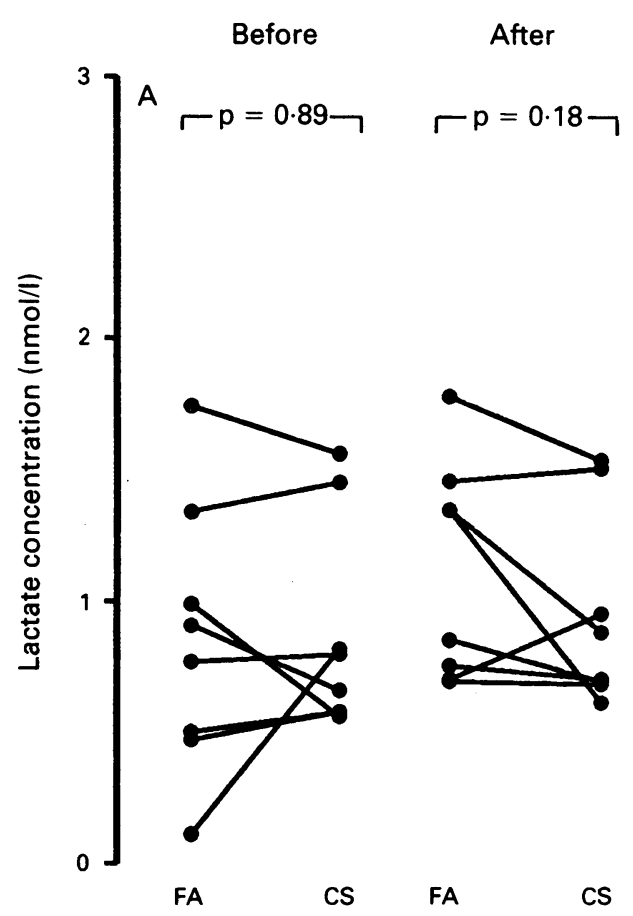

stimulated a higher superoxide anion production than plasma from simultaneously taken arterial blood (table 2) and plasma from coronary sinus blood before balloon inflation (median difference: $1.28(0.19,2.73) \mathrm{nmol} / 5$ $\times 10^{5}$ cells $\left./ 15 \mathrm{~min} ; \mathrm{p}=0.004\right)$. Neither plasma stimulated superoxide anion production nor plasma chemoattractiveness showed any significant arterial and venous blood differences under resting conditions or changes in arterial blood after balloon deflation.

In the control group, there were no significant differences between arterial and coronary sinus blood in the effect of plasma on normal neutrophils (figs $2 \mathrm{~A}$ and $3 \mathrm{~A}$ ). Neither did normal neutrophils respond differently to plasma from the coronary sinus before and

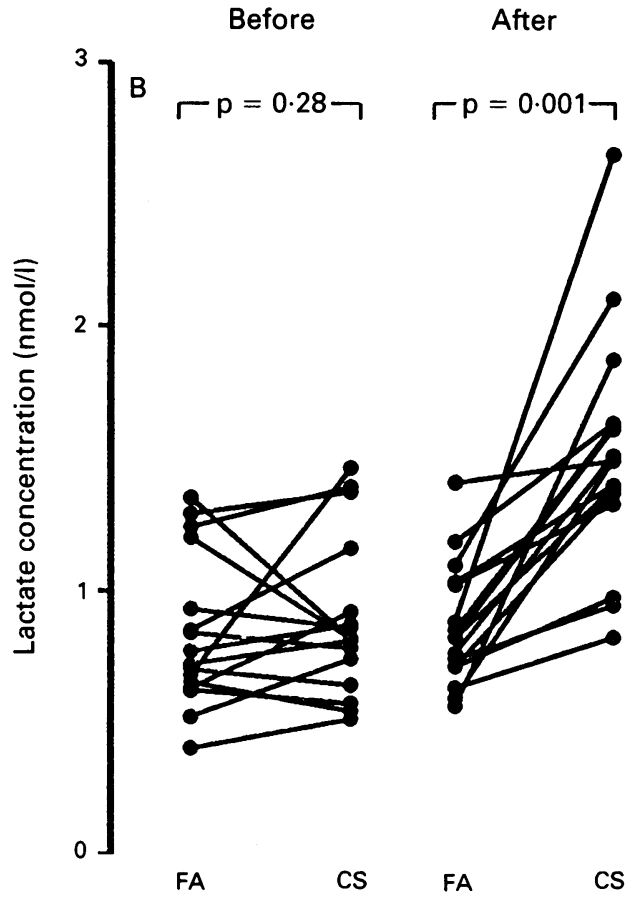

after balloon inflation (figs 2(A) and 3(A)).

Differences in the effects of patient plasma from arterial and coronary sinus blood on control neutrophils immediately after balloon deflation were significantly greater in the study group compared with the controls (table 2).

FUNCTIONAL CHANGES IN NEUTROPHILS

Neutrophil counts did not show any significant differences between arterial and coronary sinus blood in either group (table 2).

In the study group, immediately after balloon deflation coronary sinus blood contained a higher proportion of nitro blue tetrazolium positive neutrophils than coronary sinus
Figure 2 Plot of FA and $C S$ blood differences in chemoattractiveness of plasma to control neutrophils before and immediately after the first balloon inflation $(A)$ in the control group (brief balloon inflation) and (B) in the study group,

(balloon inflation for two minutes). Abbreviations and statistics as for fig 1 .

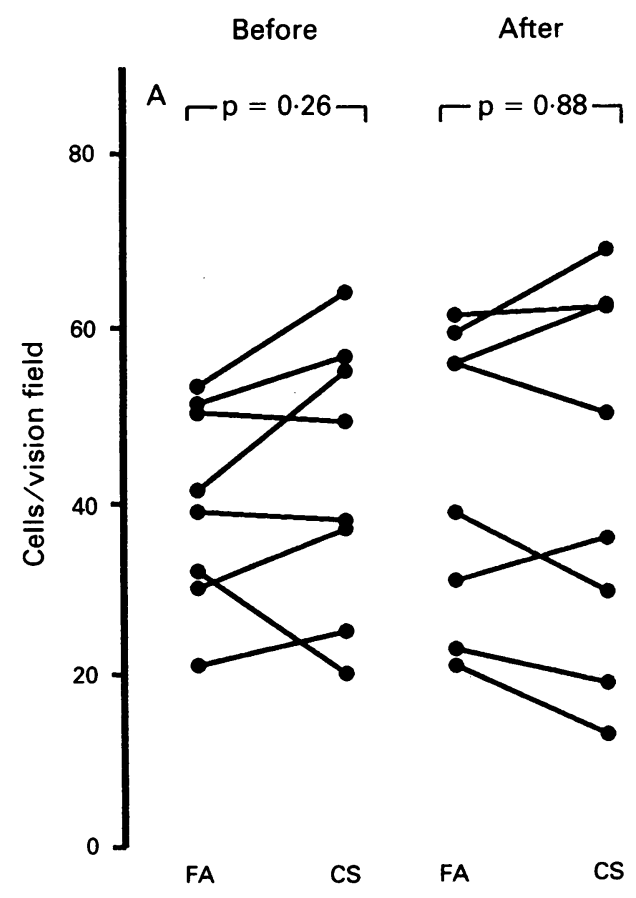

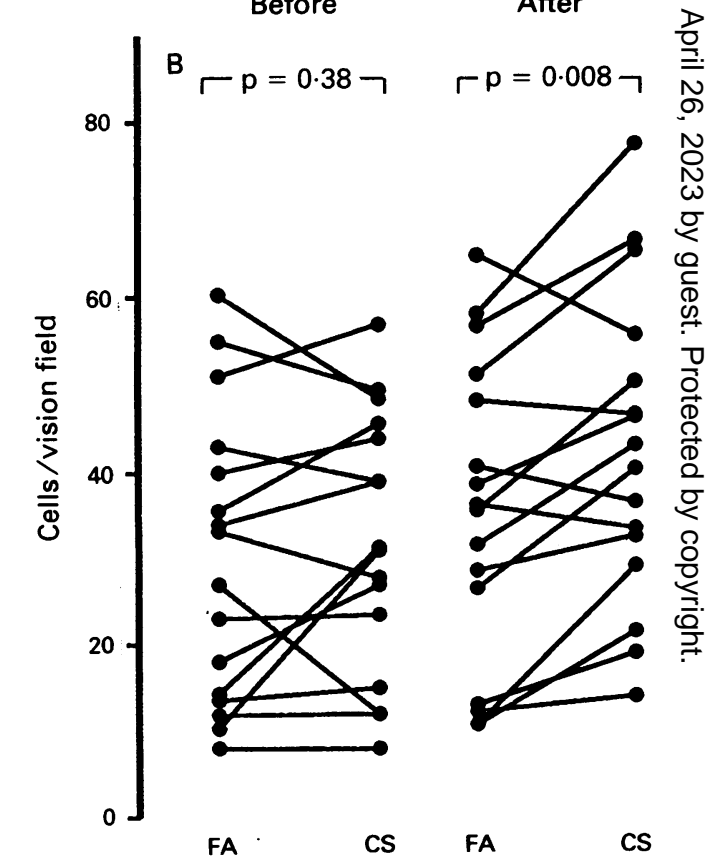


Figure 3 Plot of $F A$ and CS blood differences in plasma stimulated superoxide anion production by control neutrophils before and immediately after the first balloon inflation $(A)$ in the control group (brief balloon inflation) and (B) in the study group (balloon inflation for two minutes). Abbreviations and statistics as for fig 1 .
Figure 4 Plot of $F A$ and $C S$ blood differences in nitro blue tetrazolium (NBT) score before and immediately after the first balloon inflation $(A)$ in the control group (brief balloon inflation) and $(B)$ in the study group (balloon inflation for two minutes). Abbreviations and statistics as for fig 1 .

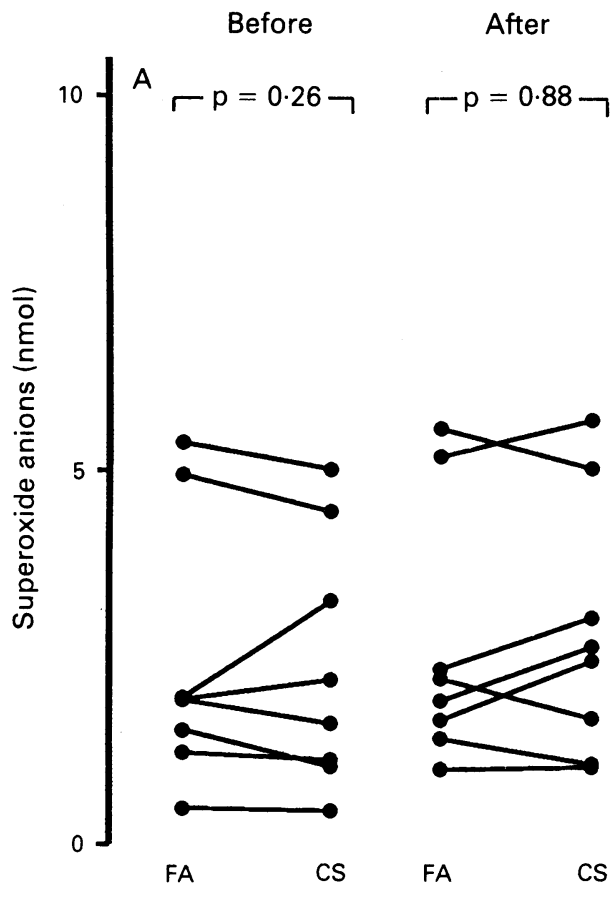

blood before balloon inflation (median difference: $3 \cdot 2 \%(1 \cdot 6 \%, 4 \cdot 1 \%), p=0 \cdot 001$, fig $4 \mathrm{~B})$. Furthermore, after balloon deflation filterability of neutrophils taken from coronary sinus blood was significantly lower than that before balloon inflation (median difference: -0.095 $(-0.013,-0.185), \quad p=0.004$, fig 5B). Similar changes in the arterial blood were not found. Thus significant differences between arterial and coronary sinus blood nitroblue tetrazolium score (fig 4B) and in late relative filtration rate of neutrophils (fig 5B) were found immediately after balloon deflation (table 2).

In the control group, comparison of neutrophil data before and after balloon inflation did not show any differences; nor were there

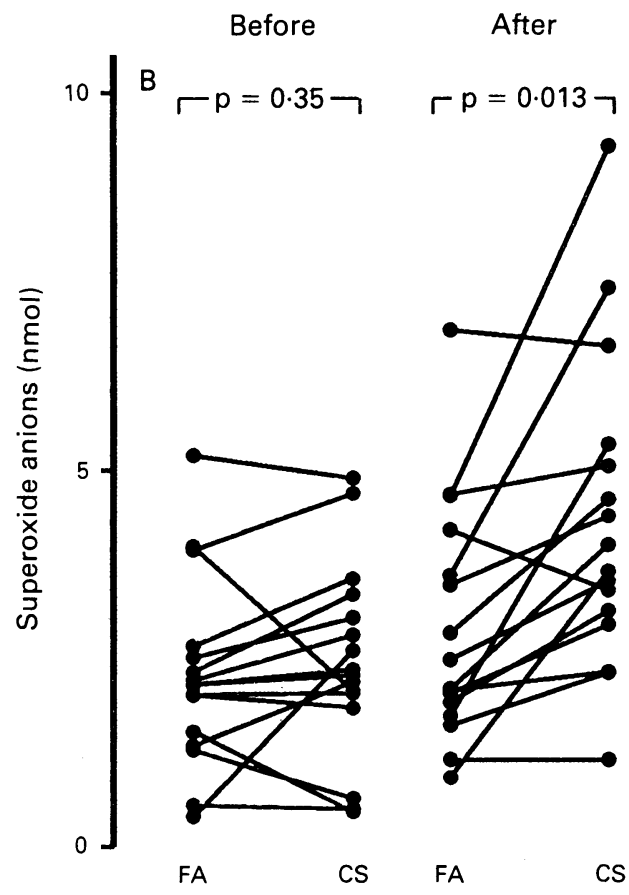

any significant differences between arterial and coronary sinus blood before or after balloon inflation (figs $4 \mathrm{~A}$ and $5 \mathrm{~A}$, table 2 ).

Differences between arterial and coronary sinus blood in nitro blue tetrazolium score and in late relative filtration rate of neutrophils immediately after balloon deflation were significantly more pronounced in the study group compared with the control group (table 2).

\section{Discussion}

Our present study shows for the first time that the heart, transiently rendered ischaemic by coronary artery occlusion during PTCA releases chemoattractants for neutrophils.
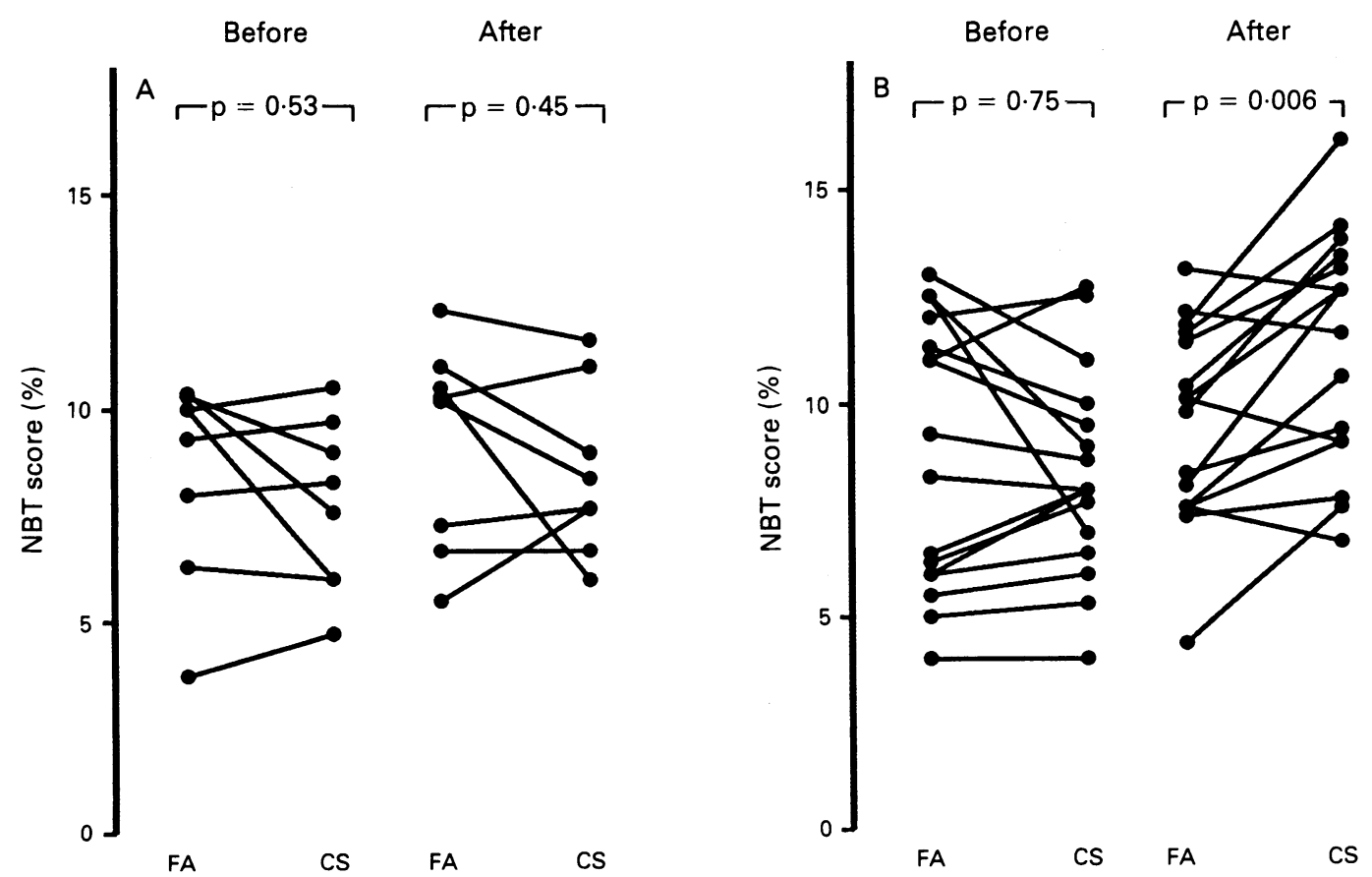
Figure 5 Plot of FA and CS blood differences in late relative filtration rate before and immediately after the first balloon inflation $(A)$ in the control group (brief balloon inflation) and (B) in the study group (balloon inflation for two minutes). Abbreviations and statistics as for fig 1 .

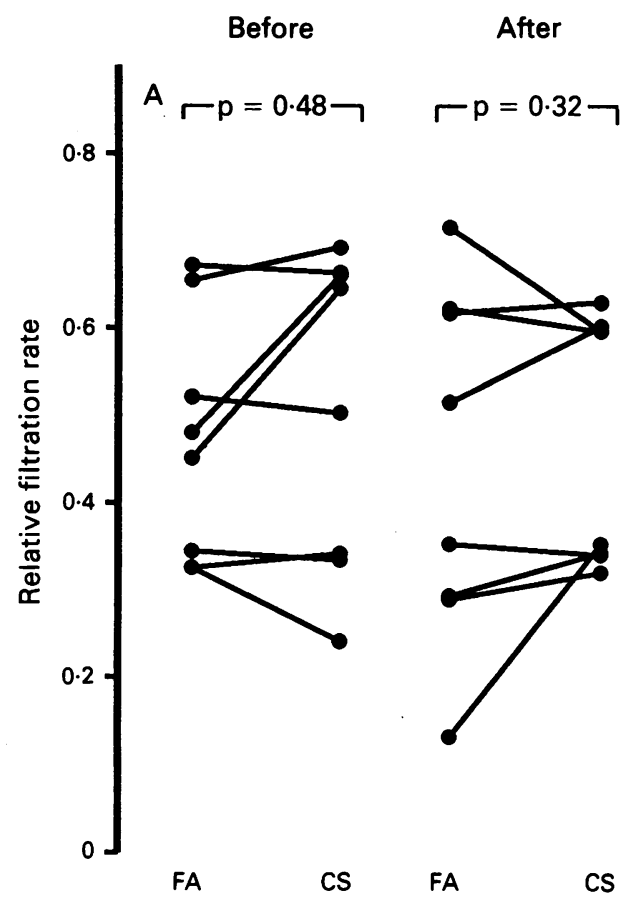

This was shown by increased chemotaxis of normal neutrophils towards plasma from the coronary sinus blood of the ischaemic heart. The potential of these chemoattractants for stimulating neutrophils was indicated by an enhanced superoxide anion production in normal neutrophils after preincubation with plasma from the coronary sinus blood of the ischaemic heart. Similar neutrophil activation, as found in normal neutrophils after preincubation with patient plasma, was found in the patients' native neutrophils immediately after transient myocardial ischaemia by balloon inflation, the coronary sinus blood contained more activated neutrophils with reduced deformability than did the arterial blood.

Cardiac release of chemoattractants with concomitant neutrophil activation was only found, if substantial myocardial ischaemiaas shown by myocardial lactate release and ST segment changes-was induced by balloon inflation. If, however, balloon inflation was brief $(<10 \mathrm{~s})$ and did not cause any significant myocardial lactate release or ST segment changes, no significant alterations in neutrophil function and plasma chemoattractiveness were found.

It is known from animal experiments ${ }^{22}{ }^{23}$ as well as from studies in patients with peripheral arterial occlusive disease ${ }^{11}$ that ischaemia below the threshold of irreversible cell damage may alter neutrophil function. In coronary artery disease, however, the changes in neutrophil function, as yet, could not be related to myocardial ischaemia. ${ }^{8-10}$ In a previous study on granulocyte activation after PTCA, interpretation of the data concerning the role of ischaemia was hampered by multiple non-standardised balloon inflations, by varying amounts of contrast media given, and by the lack of a control group or verification of myocardial ischaemia by metabolic alterations. ${ }^{10}$ In our study, an identical protocol

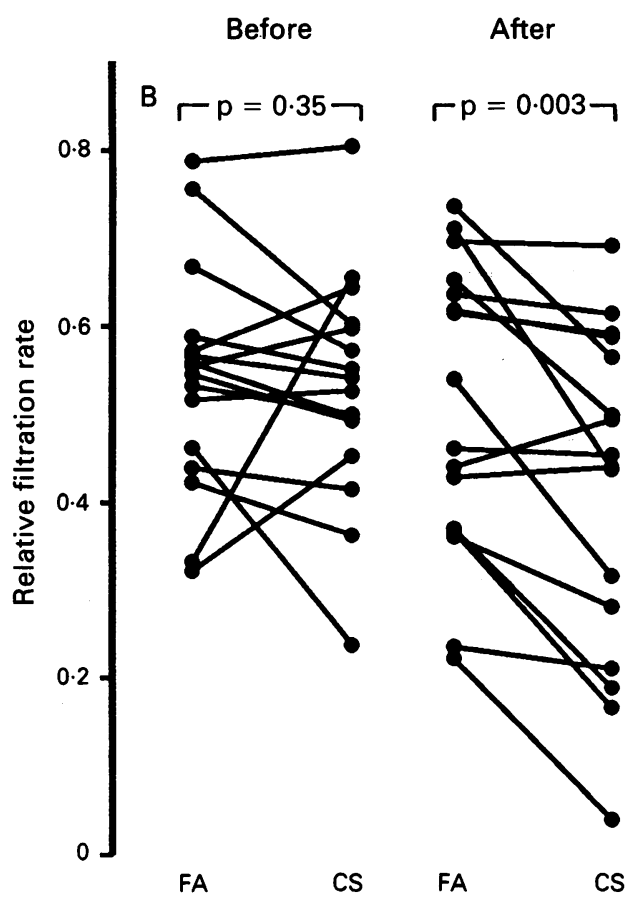

was applied to the control group and to the study group except for the duration of balloon inflation. This resulted in a significant difference in the extent of myocardial ischaemia between the two groups. With respect to plaque fissuring and endothelial tearing during balloon inflation, no substantial differences between the two groups are to be anticipated, as in both groups full balloon expansion was achieved with essentially the same inflation pressures. The present study, therefore, strongly suggests that the local release of chemoattractants with concomitant neutrophil activation is caused by myocardial ischaemia.

\section{METHODOLOGICAL CONSIDERATIONS}

Changes in coronary sinus blood must be assumed to reflect only part of the changes in the ischaemic area of the heart, as the coronary sinus receives only about $50 \%$ of its blood from the LAD region. ${ }^{24}{ }^{25}$ Moreover, the plasma specimens taken for analysis may contain only part of the mediators generated in myocardial ischaemia. Despite immediate cooling and processing, some of the mediators with short biological half lives, in particular adenosine ${ }^{26}$ and arachidonic acid metabolites, ${ }^{27}$ are not effective under the given experimental set up. The most likely mediators of the increase found in chemotactic activity are, therefore, more stable compounds, such as cytokines (for example, interleukins 6 and $8^{2829}$ ) complement fractions, ${ }^{30}$ thrombin, ${ }^{31}$ and platelet activating factor. ${ }^{32}$ Further studies with receptor antagonists may enable the mediators of the neutrophil responses to plasma from ischaemic myocardium to be identified.

In previous studies, ${ }^{8-10}$ interpretation of changes in neutrophil function was hampered by possible artefacts occurring during the separation procedure. In our study, increased neutrophil function found after transient 3 , 
myocardial ischaemia during PTCA is primarily based on the examination of unseparated neutrophils from freshly drawn samples from the nitro blue tetrazolium test. As neutrophil activation leads to a loss of passive deformability, ${ }^{33-35}$ filtrometry was used as an additional index for the degree of neutrophil activation. Filtrometry can be performed with anticoagulation by EDTA. At the expense of a potential underestimation of the in vivo changes, the use of EDTA minimises spontaneous activation and neutrophil aggregation during separation. ${ }^{36}$ Neutrophil filtration is, therefore, hardly affected by separation artefacts. ${ }^{36}$

In the experiments on the effect of patient plasma on normal neutrophils, separation induced modifications of neutrophil function cannot contribute to the variations within individual patients. This was assured by the use of control neutrophils from the same separation procedure for each specimen of one patient. At least part of the variation between individual patients in the effect of patient plasma on control neutrophils, however, must be attributed to the experimental design, as the control neutrophils were taken from different donors for different patients. For this reason, no attempt was made to correlate the extent of stimulation of control neutrophils by patient plasma with the degree of activation in patient neutrophils or with the extent of release of myocardial lactate.

It is not impossible that neutrophil function and mediator release is affected by the treatment with aspirin ${ }^{37}$ or the exposure of blood cells to the foreign material introduced by the balloon. The changes associated with ischaemia however, cannot be attributed to these effects, as they did not differ between the control and the study group and were effective both under resting conditions and after balloon deflation.

\section{PATHOPHYSIOLOGICAL CONSIDERATIONS}

Release of chemoattractants and neutrophil activation immediately after myocardial ischaemia caused by balloon inflation could be the consequence of an interaction between blood cells and endothelial cells. ${ }^{4-6}$ This interaction is facilitated by the prolonged contact between blood cells and endothelial cells under low (or zero) shear stresses and by an accumulation of inflammatory mediators that are neither washed off nor counterbalanced by inflowing endogenous inhibitors. ${ }^{4-6}$ Potential mediators of a mutual modification of cell function between blood cells and endothelial cells include platelet activating factor $^{32} 38$ tumour necrosis factor, ${ }^{39} 40$ interleukins 6 and $8,{ }^{2841}$ and vasoactive arachidonic acid metabolites. ${ }^{4243}$ Furthermore, complement 1q fixation may occur at activated adherent neutrophils resulting in the formation of chemotactic complement fractions. ${ }^{70}$

Consistent with these concepts, cardiac release of vasoactive substances has been shown in patients with coronary artery disease. ${ }^{44}$ Our study shows, for the first time, a release of chemoattractants with concomitant neutrophil activation in the ischaemic human heart during PTCA. Endothelial cell blood cell interactions with mutual cell activation may, therefore, be assumed to start early during myocardial ischaemia.

The local leucocyte activation may cause progressive cytotoxicity resulting in microvascular injury and even tissue damage. ${ }^{1}$ The findings of our study may, therefore, help to explain the delayed functional recovery after PTCA, as indicated by: (a) delayed recovery to normal of coronary vascular reserve ${ }^{45}(b)$ prolonged diastolic dysfunction, ${ }^{46}$ and (c) delayed resolution of exercise induced abnormalities on thallium-201 and glutamate-N-13 scintigraphy. ${ }^{47} 48$ Moreover, priming of various neutrophil and endothelial cell functions by mediator release may contribute to the cumulative detrimental effects of repetitive ischaemic episodes on coronary vasomotor reserve, ${ }^{49}$ myocardial function, ${ }^{50}$ and viability. ${ }^{51}$

In summary, our study shows a local release of chemoattractants with concomitant neutrophil activation after coronary occlusion for two minutes during PTCA, which is not found after brief $(<10 \mathrm{~s})$, but full balloon inflation. These findings may be explained by endothelial cell blood cell interactions with production of mediators, starting in the early course of myocardial ischaemia. The early changes in neutrophil function during myocardial ischaemia may contribute to the ischaemic injury.

This study was supported by a grant from the Deutsche Forschungsgemeinschaft (SFB 320), Bonn-Bad Godesberg, Germany. We thank Mrs Anita M Neumann for editorial help.

1 Mehta JL, Nichols WW, Mehta P. Neutrophils as potential participants in acute myocardial ischaemia: relevance to reperfusion. $\mathcal{f} \mathrm{Am}$ Coll Cardiol 1988;11: 1306-16.

2 Engler RL, Dahlgren MD, Morris DD, Peterson MA Schmid-Schönbein GW. Role of leucocytes in the response to acute myocardial ischaemia and reperfusion in the dog. Am f Physiol 1986;251:H314-22.

3 Gruber HE, Hoffer ME, McAllister DR, Laikind PK Lane TA, Schmid-Schönbein GW, et al. Increased adenosine concentration in blood from ischaemic myocardium by AICA riboside. Effects on flow, granumyocardium by AICA riboside. Effects on flow,

4 Dinerman JL, Mehta JL. Endothelial, platelet and leucocyte interactions in ischaemic heart disease: insights into potential mechanisms and their clinical relevance. $\mathcal{f} \mathrm{Am}$ Coll Cardiol 1990;16:207-22.

5 Braquet P, Hosford D, Braquet M, Bourgain R, Bussolin $\mathrm{F}$. Role of cytokines and platelet-activating factor in microvascular immune injury. Int Arch Allergy Appl Immunol 1989;88:88-100.

6 Neumann FJ, Tillmanns H, Kübler W. Hemorheologica abnormalities in acute coronary syndromes: cause or consequence? Clin Hemorheol 1990;10:601-11.

7 Rossen RD, Swain JL, Michael LM, Weakley S, Giannini $\mathrm{E}$, Entmann ML. Selective accumulation of the first component of complement and leucocytes in ischaemic component of complement and leucocytes in ischaemic canine heart muscle: a possible initiator of an extra myocardial mech

8 Mehta IL, Dinerman J, Mehta P, Saldeen TGP, Lawson D, Donnelly WH, Wallin R. Neutrophil function in ischaemic heart disease. Circulation 1989;79:549-56.

9 Ricevuti R, De Servi S, Mazzone A, Angoli L, Ghio S Specchia G. Increased neutrophil aggregability in coronary artery disease. Eur Heart $\mathcal{F} 1990 ; 11: 814-8$.

10 De Servi S, Mazzone A, Ricevuti G, Fioravanti A Bramucci E, Angoli L, et al. Granulocyte activation afte coronary angioplasty in humans. Circulation 1990 82:140-6.

11 Neumann FJ, Waas W, Diehm C, Weiss T, Haupt H 
deformability of neutrophils after intermittent claudication. Circulation 1990;82:1122-9.

12 Mitchinson MJ, Ball RY. Macrophages and atherogenesis. Lancet 1987;ii:146-9.

13 Ellis SC, Vandormael MC, Cowley MJ, DiSciascio G, Deligomel M, Topol EJ, et al. Coronary morphologic
and clinical determinants of procedural outcome with angioplasty for multivessel disease. Circulation 1990;82: angioplasty

14 Campeau L. Grading of angina pectoris. Circulation 1976;54:522-3.

15 Boyum A. Isolation of mononuclear cells and granulocytes from human blood. Scand $\mathcal{F}$ Clin Lab Invest 1968;97: 77-110.

16 Vercelotti GM, Sweder van Asbeck B, Jacob HS. Oxygen radical-induced erythrocyte hemolysis by neutrophils. Critical role of iron and lactoferrin 7 Clin Invest 1985;76:956-62.

17 Boyden SV. The chemotactic effect of mixtures of antibody and antigen on polymorphonuclear leucocytes. $\mathcal{F}$ Exp Med 1962:115:453-66.

18 Falk W, Harvath L, Leonard EJ. A 48-well microchemotaxis assembly for rapid and accurate measurement of taxis assembly for rapid and accurate measurement of leucocyte

19 Babior BM, Kipnes RS, Curnutte JT. Biological defense mechanisms. The production by leucocytes of superoxide, a potential bactericidal agent. $\mathcal{F}$ Clin Invest 1973;52:741-3.

20 Park BH, Fikrig SM, Smithwick EM. Infection and nitroblue-tetrazolium reduction by neutrophils: A diagnostic aid. Lancet 1968;ii:532-4.

21 Nash GB, Jones JG, Mikita J, Dormandy JA. Methods and theory for analysis of flow of white cell subpopulations through micropore filters. Br $\mathcal{F}$ Haematol 1988; 70:165-70.

22 Engler RE, Covell JW. Granulocytes cause reperfusion ventricular dysfunction after 15 minute ischaemia in the ventricular dysfunction after

23 Westlin W, Mullane KM. Alleviation of myocardial stunning by leucocyte and platelet depletion. Circulation 1989;80:1828-36.

24 Ganz W, Tamura K, Marcus HS, Donose R, Yoshida S, Swan HJC. Measurement of coronary sinus blood flow by continuous thermodilution in man. Circulation 1971 44:181-7.

25 Nakazawa HK, Roberts DL, Klocke FJ. Quantitation of anterior descending versus circumflex venous drainage in the canine great cardiac vein and coronary sinus. $A m$ in Physiol 1978;234:H163-9.

26 Ontyd J, Schrader J. Measurement of adenosine, inosine and hypoxanthine in human plasma. 7 Chromat 1984 and hypoxan

27 Gryglewski RJ, Botting RM, Vane JR. Mediators produced by the endothelial cell. Hypertension 1988;12: 530-48.

28 Borrish L, Rosenbaum R, Clark S. Activation of neutrophils by recombinant interleukin 6 . Cellula Immunology 1989;121:280-9.

29 Maestrelli P, Tsai JJ, Cromwell O, Kay AB. The identification and partial characterization of a human mononuclear cell-derived neutrophil chemotactic factor apparently distinct from II-1, IL-2, GM-CSF, TNF and IFN-gamma. Immunology 1988;64:219-25.

30 Kownatzi $\mathrm{E}$, Uhrich S. Production of superoxide anion and hydrogenperoxide by human neutrophil granuloand hydrogenperoxde by human neutrophil granulocytes during chemotactic migration towards f-MetLeu-Phe, $\mathrm{C} 5 \mathrm{a}$, leukotriene $\mathrm{B}_{4}$, monocyte-derived
chemotaxin/ $\mathrm{HL}-8$ and platelet-activating factor. Int Arch chemotaxin/IL-8 and platelet-activating

31 Morin A, Marchand Arvier M, Doutremepuich F, Vigneron C. Coagulation impact on chemotactic activity generation for polymorphonuclear leukocytes. Thromb Res 1990;59:979-84.

32 Ingraham LM, Coates TD, Allen JM, Higgins $C P$, Baehner RL, Boxer LA. Metabolic, membrane, and functional responses of human polymorphonuclear leucocytes to platelet activating factor. Blood 1982;59: cocytes to

33 Schmid-Schönbein GW, Skalak R, Sung KPL, Chien S. Human leucocytes in the active state. In: Bagge U, Born GV, Gaethgens P, eds. White Blood Cells, Morpholog and Rheology as related to Function. The Hague: Martinus Nijhoff, 1984:21-31.
34 Chien S, Sung KL, Schmid-Schönbein GW, Skalak R, Schmalzer EA, Usami S. Rheology of leucocytes. Ann NY Acad Sci 1987;516:333-47.

35 Howard TH, Oresajo CO: The kinetics of chemotactic peptide-induced change in F-actin content, F-actin distribution and the shape of neutrophils. $¥$ Cell Biol 1985; 101:1078-85.

36 Nash GB, Jones JG, Mikita J, Christopher B, Dormandy JA. Effects of preparative procedures and of cell activation on flow of white cells through micropore filters. $\mathrm{Br}$ f Haematol 1988;70:171-

37 Colli S, Caruso D, Tremoli E, Stagliotto E, Morazzoni G Galli G. Effect of single oral administrations of non steroidal inflammatory drugs on healthy volunteers on arachidonic acid metabolism in peripheral polymorphonuclear and mononuclear leukocytes. Prostaglandins Leukot Essent Fatty Acids 1988;34:167-74.

38 Chignard $M$, Le Couedic JP, Tence $M$, Vargaftic BB, Benviste J. Platelet-activating factor (PAF-acether) secretion from platelets. Effect of various aggregating agents. Br $\mathcal{F}$ Haematol 1980;46:455-64.

39 Richter J, Andersson T, Olsson I. Effect of tumor necrosis factor and granulocyte/macrophage colony-stimulating factor on neutrophil degranulation. $f$ Immuno 1989;142:3199-205.

40 Camussi G, Tetta C, Bussolino F, Baglioni C. Tumor necrosis factor stimulates human neutrophils to release leukotriene B4 and platelet-activating factor. Eur $\mathcal{f}$ Biochem 1989;182:661-6.

41 Yoshimura T, Matsushima K, Tanaka S, Robinson EA, Appella E, Oppenheim JJ, et al. Purification of human monocyte-derived neutrophil chemotactic factor that shares sequencing homology with other host defense cytokines. Proc Natl Acad Sci USA 1987;84:9233-5.

42 Weissmann G, Smolen JE, Korchak HM. Release of inflammatory mediators from stimulated neutrophils. $N$ Engl f Med 1980;303:27-34.

43 Evers AS, Murphree S, Saffitz JE, Jakschik BA Needlemen P. Effects of endogenously produced leukotrienes, thromboxane, and prostaglandins on coronary vascular resistance in rabbit myocardial infarction. f Clin Invest 1985;75:992-9.

44 Rubanyi GM, Frye RL, Holmes DR, Vanhoutte PM Vasoconstrictor activity of coronary sinus plasma from patients with coronary artery disease. $7 \mathrm{Am}$ Coll Cardio 1987;9:1243-9.

45 Vaterrodt D, Dirschinger J, Dacian S, Rudolph W. Normalization of coronary flow reserve within 24 hours post PTCA [abstract]. Circulation 1990;82(suppl III): 626.

46 Wijns W, Serryus PW, Slager CJ, Grimm J, Krayenbüh HP, Hugenholtz PJ, et al. Effect of coronary occlusion during percutaneous transluminal angioplasty in humans on left ventricular chamber stiffness and regional diastolic pressure-radius relations. $\mathcal{F} \mathrm{Am}$ Coll Cardio 1986;7:455-63.

47 Manyari DE, Knudtson $M$, Kloiber $R$, Roth $D$ Sequential thallium-201 myocardial perfusion studies after successful percutaneous transluminal coronary artery angioplasty: Delayed resolution of exerciseinduced scintigraphic abnormalities. Circulation 1988; 77:86-95.

48 Zimmermann $R$, Helus $F$, Knapp WH, Tillmanns $H$ Eisenhut M, Neumann FJ, et al. Prolonged metabolic alterations in ischaemic human myocardium after successful angioplasty detected by repeated investigations with N-13 glutamate. In: Höfer $\mathrm{R}$, Bergmann $\mathrm{H}$, eds. with N-13 glutamate. In: Höfer $\mathrm{R}$, Bergmann $\mathrm{H}$, eds. Radioactive Isotopes in Clinical Medicine

49 Tillmanns H, Neumann FJ, Parekh N, Müller-Bühl U, Waas W, Haupt HM, et al. Microcirculatory disturbances and white blood cell activation during ischaemia. In: Meßmer K, ed. Ischaemic diseases and microcirculation-new insights. München: Zuckerschwerdt, 1990 33-9.

50 Neumann FJ, Tiefenbacher C, Mohler T, Ott I, Parekh $\mathrm{N}$, Steinhausen $\mathrm{M}$, et al. Decreased myocardial blood flow after repetitive ischaemia and reperfusion of the rat heart: Cause or consequence of myocardial stunning [abstract]? Circulation 1991;84(suppl II):656.

51 Geft IL, Fishbein MC, Ninomiya K, Hashida J, Chaux E, Yano J, et al. Intermittent brief periods of ischaemia have a cumulative effect and may cause myocardial necrosis. Circulation 1982;66:1150-3. 